可視化情報 Vol. 10 Suppl. No. 2 (1990年11月)

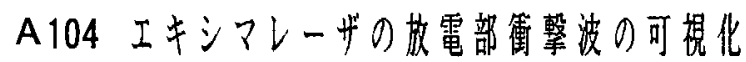

\author{
株式会社東芝小杉伸一郎 $\mathrm{O}$ \\ 株式会社東芝 大石高志 \\ FLOW VISUALIZATION OF SHOCK RAVES IN A EXCIMER LASER
}

Shinichiroh KOSUGI* and Takashi OHISHI *

\begin{abstract}
Experimental study on shock aves in a high repitation rate excimer laser has been carried out. In a high repitation rate excimer laser. shock waves in subsonic loop are induced by the active medium excitation by means of pulse discharge. Shock waves in He gas by a pulse discharge are visualized by schlieren method using a scale discharge section model, CCD camera. stroboscope. and digital image memory which used to take photographes. Shock waves from anode surface, cathode surface, discharge region, and pin sparks for preionization are observed. Shock aves reflect at anode and cathode surfaces alternately for several times. Shock waves from dischrage region travel through channel.
\end{abstract}

1.はじめに

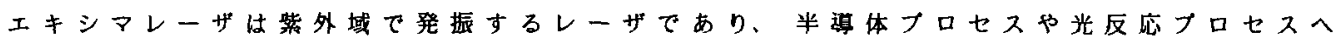
の忘用が期待されている。エキシマレーザ X e / H C l または K r / F 2 の湿合ガスを Heまたは $\mathrm{N}$ eで希釈したレーザカス中で強いバルス放電を行いレ一ザガスを励起し発振 させることで得られる。バルス発振で高い平均出力を得るためにはレーザ発振の高綠り返 し化が必要である。ところがエキシマレーザの高綝り返し化には限界が存在し、その1つ の原因として衛撃波が考えられている。レーザカスを励起するためにバルス放電を行うと 衙撃波が発生し、この衝整波がつきの放電時に放電㫣梗間に密度の摇らををひきおこし アーキングを誘起するため、次のレーザガスを均ーに励起することが困蓶になると考えら れているは1は13111。

エキシマレーザの放電部で発生する衝撃波についての研究は少なく、放電部での衙慗波 と放電現舜の関係は明らかになっていない。本研究でエキシマレーザの放電部スケール

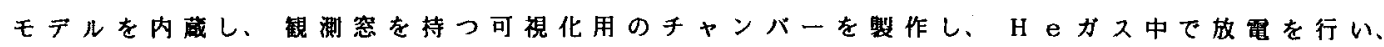

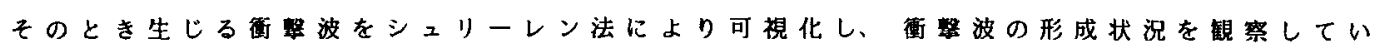
る。写真は C C Dカメラとストロホ、、テシタルメモリを使用して撮影した。

* HEAVY apPaRATUS ENGINEERING LabORATORY, TOSHIBA CORPORATION 2-4. SUEHIRO-CHO, TSURUHI-KU, YOKOHAMA, 230 JAPAN 


\section{2. 実呀装置および方法}

エキシマレーザ放龟部モデルの光軸方向からみた放電部断面図をFig.1に示す。主放歶電 極は上がアノード、下がカソードになっており、電掩は紙面の垂直方向に䄪 $300 \mathrm{~mm}$ 長さを 持つ。主放電電㥛の雨期に予俌電離のための放電とンがならんている。この放電部モデル を可視化チャンバー内に設算して实験を行う。カスは Heを使用し、ガス正力は1300tor とする。衝揧波の䚁察が目的であるのでガス恃静止状態にて観察を実施した。放電回路を Fig.2に示す。放電回路は容嫼移行型であり、主コンデサCsは13.3nF、ビーキングコンデ ンサCp仕11.9nFである151。コンデンサの充電電王は24kVである。本実験では練り返し連転 を行わないのでスイッチはギャップスイッチG.P.を使用している。Fig.3に可視化方法を示 す。閃光時間が半值幅で75nsと短いストロボ(菅原技研ナノバルスラナトNP-1A）を光源と してシュリーレン法により放電電極間を可視化する。写真はCCDカメラとデタルメモリ (菅原技研ストロホヒビョンスコーフ SuS-2)、 V T Rを使用して层影する。テシタルメモ リはストロボの発光時にCCDカメラに写った画像を一時的に記録するために使用される。放 電後、任意の時間にストロボを発光させそのときのシュリーレン像をCCDカメラとデシタル メモリを使用して撮影し、V V R R 記録する。放電後ストロボを発光させるタイミングは リターター（菅原技研 $\mathrm{BE}-306$ )を使用して調整する。放電実瑍を繰り返し行い遅延時間を 変えて撮影していくことで連続したビデオ画像が得られる。

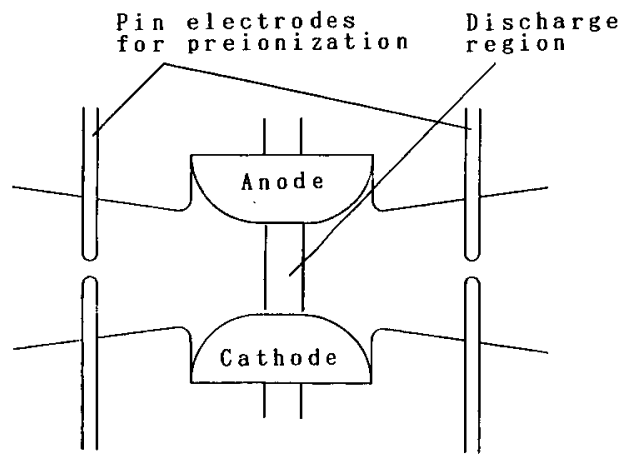

Fig. 1 Discharge section

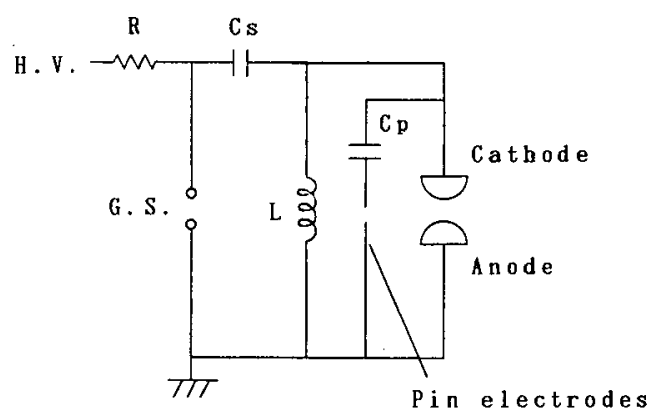

Fig. 2 Electric circuit

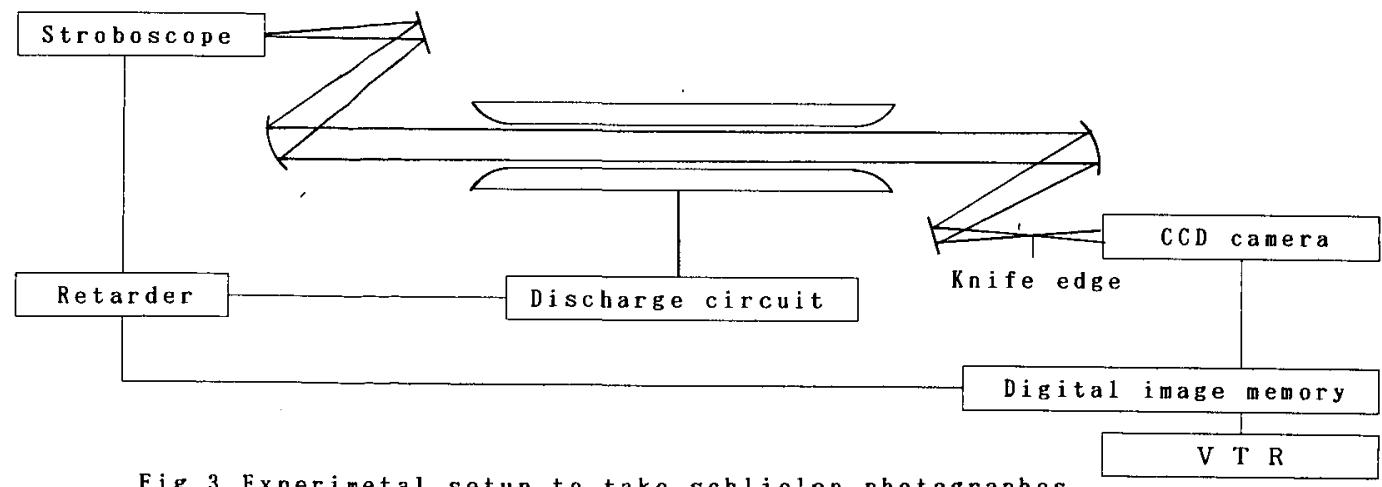

Fig. 3 Experimetal setup to take schlielen photographes 


\section{3. 実験結果と考察}

Fig. 4 とFig.5にナイフエッジを水平においた場合のそれぞれ放電後 $5 \mu \mathrm{s} 、 20 \mu \mathrm{s}$ 後の可視 化写真を示す。写真から主放電電極の表面から衝撃波が発生していることがわかる。かり 一ドから発生する衙撃波はアノードから発生する衝撃波よりも強くなっている。また、予 備放電ピンからも衝撃波が発生している。これらの衙撃波は上下の壁面に反射されて何度 も往復する。Fig.6と Fig.7にナイフエッジを垂直においた埸合のそれぞれ放電後5 $\mu \mathrm{s}$ 、 $10 \mu \mathrm{s}$ の可視化写真を示す。放電空間から流路方向に衝撃波が発生していることかわかる。 これらの写真から放電部には主放電電極のアノート゚とカソードの表面から発生する上下方 向の衝撃波、予備電離ピンから発生する球状の衝撃波、主放電電極間の放電空間から横に 広がっていく衙撃波の 3 種の畐撃波が発生していることがわかる。

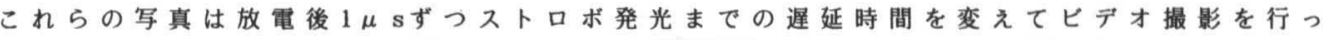
ている。ビデオ撮影により現象を連続的に見ることができ、衝撃波の生成から減衰までを 観察することができた。ただし、実験で使用したガスは $\mathrm{H}$ e ガスであるので音速が速い。 そのため現象は実際のレーザガスよりも速くなっていると考えられる。

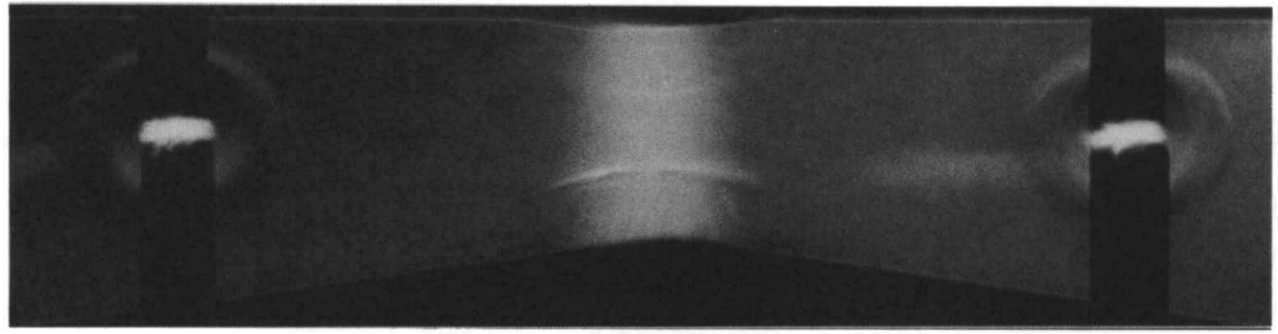

Fig. 4 Schlielen photograph at $5 \mu$ s after discharge (Knife edge is set horizontally)

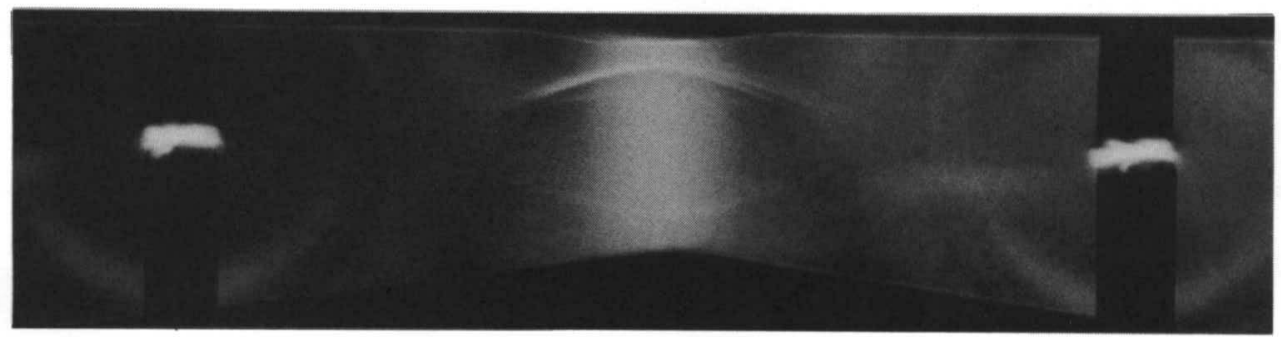

Fig. 5 Schlielen photograph at $20 \mu$ s after discharge

(Knife edge is set horizontally) 


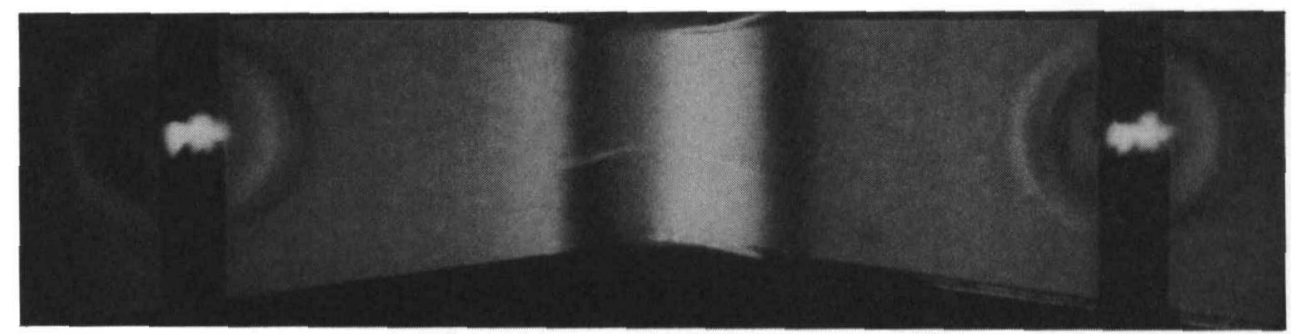

Fig. 6 Schlielen Photograph at $5 \mu$ s after discharge (Knife edge is set vertically)

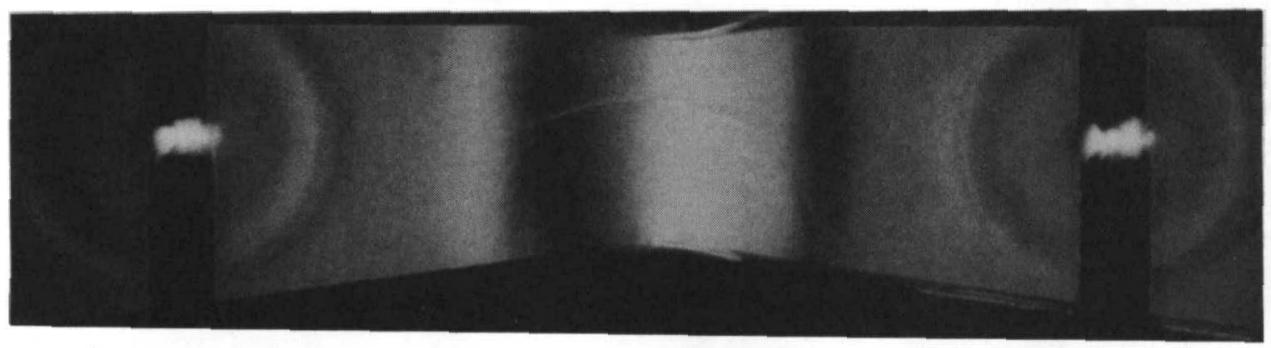

Fig. 7 Sch1ielen Photograph at $10 \mu$ s after discharge

(Knife edge is set vertically)

4. まとめ

エキシマレーザ放電部に発生する衝撃波を閃光時間の短いストロボを光源として可視化 実験を行い、CCDカメラ、デジタルメモリを使用して連繞な画像としてVTRに収録した。 エキシマレーザの放電部の衙撃波の発生と伝播を連䌇な画像としてとらえることができた。 エキシマレーザの放電部にはカソードとアノードの表面から発生する衜撃波、放電空間か

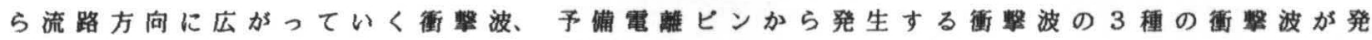
生することが明らかになった。

謝 辞

本研究は、新エネルギ-・産業技術縔合開発機構の大型工業技術研究開発「超先端加工 システムの研究開発の一棵としてなされたものである。

\section{参考文献}

(1) M.L.Sentis et a1., J.Appl.Phys.66,1925 (1989)

(2) V.M.Borisov et a1.. Sov.J.Quantum E1ectron.17,595 (1987)

(3) S.Takagi et a 1. CLE0'90 Technical digest, 348 (1990)

（4）柿崎他、プラスマ研究会資料 EP-90-77 (1990)

（5）高木他、光・量子デパイス研究会資料 0QD-89-8 (1989) 